Ekren, N. / Sosyal Bilimler Araştırmaları Dergisi. 2, (2007): 204-211

\title{
Sanal Aydınlatma Tekniğinin Aydınlatma Eğitimindeki Önemi
}

\section{Nazmi Ekren ${ }^{a}$}

\section{Özet}

Aydınlatmacılığın temel konusunu 1şığın üretimi, dağıtımı, ekonomisi ve ölçülmesi oluşturur. Aynı zamanda insanın ışığa karşı davranışlarını da incelemektedir. Çağımızda aydınlatma elektrik mühendisliğinde ve mimarlıkta önemli bir yer tutmaktadır. Aydınlatılacak her alanın özel bir problem olarak analiz edilmesi gerekir. Ancak aydınlatma probleminin çözümü, 1şı̆̆ın üretiminde söz sahibi olan elektrik mühendisleriyle mimarların beraber çalışması sayesinde bulunabilir.

Ülkemizde aydınlatmanın eğitimine yakın bir geçmişte başlanmıştır. Geçmişte bilgisizlikten kaynaklanan hatalar yapılarak, bir çok uygulamada gereğinde fazla veya yanlış armatür tipleri kullanılmıştır. Üniversitelerimizde aydınlatma ayrı bir bilim dalı olarak faaliyet geçmesi ile birlikte, aydınlatma eğitiminde bilgisayar kullanımı hızla artmıştır.

Aydınlatma projelerinin hazırlanmasında bilgisayar programları gerek hesaplama, gerekse görüntüleme amacıyla kullanılabilmektedir. Tasarımcı bilgisayarla yapay ve doğal aydınlatma hesaplamalarını yapabilir. Genel olarak, aydınlatma tekniğinde bilgisayar programları armatür tasarımı, iç ve dış aydınlatma hesaplarının yapılması ve değerlendirilmesi amacıyla kullanılır. Bununla birlikte yapılan aydınlatma projelerini üç boyutlu görme yeteneğinin kazandıran sanal aydınlatma tekniğinin de eğitim de kullanılması gerekmektedir.

Anahtar Kelimeler:Aydınlatma, Aydınlatma Eğitimi, Sanal Aydınlatma

\begin{abstract}
Production, distribution, economy and measurement of light form the basic subject of illumination profession. At the same time it seraches the behaviour of human for light. In our age, illumination plays important role in electrical engineering and architecture. Every place which will be illuminated have to be analysed as a special problem. However, solution of illumination problem can be found by collective work of electrical engineers and architectures who have the right to comment on production of light.

In our country, Education of illumination has begun recently. In the past, by making mistakes because of lack of knowledge wrong or too much armature types have been used more than required. By beginning education for illumination in our universities as a individual discipline computer usage has increased rapidly in illumination education.
\end{abstract}

${ }^{a}$ Dr., Marmara Üniversitesi, Teknik Eğitim Fakültesi, İstanbul. 
Ekren, N. / Sosyal Bilimler Araştırmaları Dergisi. 2, (2007): 204-211

In the preparation of illumination projects, computer programmes can be used for purpose of both calculation and imaging. Designer can make virtual and natural illumination calculations in illumination techniques are used for purpose of designing armature, making and evaluating calculation of interior and exterior illumination. Additionally, In education it is necessary to use virtual illumination technique which gives ability to see illumination projects which have been done in 3D.

Key Words::Illumination, Illumination Education, Virtual Illumination.

\section{Giriş}

Aydınlatma, kişilerin asgari görme ihtiyacını sağlayan, ışığın üretim ve dağılımını kontrol eden, ekonomik koşullar altında görme konforuna bağlı olarak da iş verimini yükseltmeyi amaç edinen özel bir bilim dalı haline gelmiştir.

Tanımdaki amaçlara cevap veren iyi ve sürekli bir aydınlatma elde etmek için; amacının iyi tespit edilmiş olması, uygun aydınlatma düzeyinin ve tipinin tespit edilerek aydınlatma tekniğine uygun projelendirilmesi, etkinlik faktörü yüksek ışık kaynaklarının tercih edilmesi, ışı̆̆ın armatürde kaybolmasına yol açmayan ve uygun 1şık dağılımı veren armatürlerin kullanımı tercih edilmelidir.

Teknolojinin gelişmesine paralel olarak günümüzde eğitim alanındaki gelişmelerde hızlı değişimler olmaktadır. Uzaktan eğitim bunlardan biri olarak söylenebilir. Üniversitelerimizde verilen aydınlatma eğitimi büyük bir çoğunlukla teorik olarak konuyu ele almaktadır. Aydınlatma eğitiminin sanal ortamlarda verilmesi, simülasyon programları sayesinde aydınlatılacak mekanların objelerinin de yerleştirilerek 3 boyutlu olarak aydınlatılmasının yapılması eğitime büyük katkı sağlayacaktır.

\section{Aydınlatmada Bilgisayarı Önemi}

Aydınlatma, disiplinler arası bir konudur. Elektrik mühendisleri, mimarlar ve iç mimarlar görsel konforun sağlanması için aydınlatma elemanlarını ve tekniklerini kendi çalışma alanları içinde kullanmaktadırlar. Genellikle bir yapının iç veya dış mekan aydınlatmasında elektrik mühendisleri, o mekanın işlevine bağlı olarak gereken aydınlık düzeyini sağlamak için hesap yapmakta ve aydınlatma elemanlarını bu hesaba göre seçerek işlemi tamamlamaktadır. Sadece aydınlık düzeyi hesabına dayalı oluşturulan aydınlatmada, ışık kaynaklarının seçimindeki hassaslık ve önem yeterince gösterilmelidir. Mekanı tasarlayan tasarımcı, yarattığı mekandaki atmosferi 
Ekren, N. / Sosyal Bilimler Araştırmaları Dergisi. 2, (2007): 204-211

sağlayacak ışık kaynakları, aydınlatma elemanları, ve teknikleri konusunda yeterli bilgiye sahip değilse, ya da bu konulara gereken önemi vermiyorsa, sonuç doğal olarak iyi olmayacaktır.

İnsanlar, çevrelerini görsel algılamanın koşulu olan aydınlığın olanaklı kıldığı oranda görürler ve algılarlar. Herhangi bir ortamdaki görsel algılamanın kusursuz olabilmesi , için aydınlığın niceliğinin ve niteliğinin, söz konusu ortamın özelliklerine uygun bir biçimde oluşturulması gereklidir.

Bilgisayar teknolojisinin gelişmesi ile birlikte, bilgisayar yardımıyla karmaşık problemler daha hızlı bir şekilde çözülmeye başlamıştır. Klasik analitik yöntemle yapılan aydınlatma hesapları hem yorucu hem de matematiksel hataların yapılmasına imkan vermektedir. Günümüzde bilgisayar yardımı ile aydınlatma hesapları çok kısa zaman içinde yapılabilmektedir Bilgisayar programları, bundan 10 sene önce bile var olan geometrik ve diğer tanımlayıcı verilerden görüntüler elde etmek için kullanılıyordu. Günümüzde ise bu konuda sınırlarımız her geçen gün genişlemekte, pek çok yeni olanak sunulmaktadır. Bilgisayarlarda artık komple bir mimari çizimden bir fotoğrafın sunmuş olabileceği kalitede çizimler yapmak artık mümkün olabilmektedir.

\section{Sanal Aydınlatma Tekniği}

Teknolojinin gelişmesine paralel olarak günümüzde eğitim alanındaki gelişmelerde hızlı değişimler olmaktadır. Uzaktan eğitim bunlardan biri olarak söylenebilir. Üniversitelerimizde verilen aydınlatma eğitimi büyük bir çoğunlukla teorik olarak konuyu ele almaktadır. Fakat son on y1ldan beri bilgisayar ortamlarında yapılan hesaplamalar neticesinde, 3 boyutlu olarak aydınlatılacak mekanların ekran üzerinden görülmesi sağlanmaktadır.

Üniversitelerimize de verilen aydınlatma tekniği dersleriçoğunlukla aynı içeriklere sahip oldukları görülmüştür. İstanbul Teknik Üniversitesi konuyu biraz daha detaylandırarak, iç ve dış aydınlatmayı ayrı ayrı ele almıştır

Yakın bir gelecekte bilgisayar ortamlarında aydınlatma tekniği dersleri anlatılmaya başlayacaktır. Birkaç özel firma tarafında geliştirilen simülasyon programları sayesinde aydınlatılacak mekanların 3 boyutlu olarak ölçeklendirilerek ve aynı zamanda mekan içerisindeki objeleri de yerleştirerek aydınlatmalar yapmaktadır. Böylece mekanın bilgisayar ortamında nasıl aydınlatılacağı gerçeğe oldukça yakın bir şekilde yapılabilinmektedir. 
Ekren, N. / Sosyal Bilimler Araştırmaları Dergisi. 2, (2007): 204-211

\section{Aydınlatma Bilgisayar Programları Genel Bir Bakış}

Lisans eğitimi süresince öğrencilere proje dersinin yanı sıra, tasarımı destekleyici - eğitici teorik ve uygulamalı birçok ders verilmektedir.

Aydınlatma da kullanılan bilgisayar programların 3 grup altında analiz edebiliriz.

- Animasyon Programları

- $\quad$ Klasik Aydınlatma Programları

- Gelişmiş Aydınlatma Programları

Animasyon programları hareketli film ve eğlence endüstrisinde çok tercih edilen programlardır. Fakat görüntüleri gerçeğe yakın bile olsa aydınlatma hesapları açısından kullanılmazlar. Klasik aydınlatma programları aydınlatma hesap yapmakla birlikte elde edilen sonuçları 2 boyutlu olarak görüntülüye bilmektedir. Bu programlar aynı zamanda yüzeylerin ışı yansıtma çarpanlarına göre sonuç alınır. Gelişmiş aydınlatma programları 3 boyutlu olarak hesapları yapabilmektedir. Bu hem tasarımeı ve hem de kullanıcı açısından büyük bir öneme sahiptir.

Son dönemlerde ortaya çıkan aydınlatma programları ciddi birtakım problemlerin önüne geçmiş olsa da, halen kullanılmakta olan programların çoğunluğu ciddi kısıt lamalara sahiptir.

Yine birçok program sadece hiçbir iç nesnesi olmayan odaları analiz edebilmektedir. Belki de, bazı programların, bugün elektrik darboğazına yaklaşan ülkemiz için hepsinden önde yer almak durumunda olan doğal aydınlatma hesabını yapamamaları en büyük sakıncalarıdır. Çünkü doğal aydınlatma en kötü durumlarda dahi enerji tasarrufu sağlar. Buna rağmen ülkemizde aydınlatma projeleri genelde penceresiz ortam kabulü ile yapılmaktadır .

Yeni hazırlanan programlarda yukarıda sayılan problemlerin büyük ölçülerde aşılmakta olması sevindirici bir gelişmedir. Buna karşın yazılımlar genelde armatür imalatçısı firmalar tarafından geliştirilmekte ve sadece belirli, firmaların lamba ve armatür verilerini içermektedir. Bu programlar veri girişine izin vermiyorlarsa hitap edebildikleri kesimlerde daralma söz konusudur. Hatta ürünlerini içerdiği armatür imalatçısı firmaların yeni piyasaya sürülen ürünlerinin verilerinin dahi kullanılamaması programın yenilenmesi ihtiyacını doğurmaktadır. 
Ekren, N. / Sosyal Bilimler Araştırmaları Dergisi. 2, (2007): 204-211

\section{Sanal Aydınlatma Tekniğinin Eğitimdeki Yeri}

1980'lerde Lawrance Orlando Berkley Laboratuvarlarında araştırmacı olarak çalışan Gerg Ward Larson aydınlatma simulasyonu için Geriye Işın İzleme yöntemini buldu ve geliştirdi. Bu yöntemle, göze gelen ışınları yöne yani ışık kaynağına doğru izler. Bu yöntemin getirdiği bazı avantajlar vardır.

- $\quad$ Her sayıda ve şekilde objeler kullanabilir.

- Işık kaynağı, malzeme ve objeler gerçekte olduğu gibi gözükürler.

- $\quad$ Armatür şekillerinde ve çeşitlerinde bir sınırlama yoktur.

tanımlanır.

- $\quad$ Malzemeler parametre, fonksiyon, bitmap yönlü data olarak

- Yansimalar gerçekte olduğu gibidir.

- $\quad$ Gün 1şı̆̆ı ve doğal aydınlatma yapabilir.

$\mathrm{Bu}$ yöntem tamamen matematiksel ve fiziksel kurallarla hesaplama yapılır. Işının ışık kaynağından çıkıp izlediği yolları önüne çıkan engellerden yansıyarak takip eder. Bunu yaparken 1şığın en son ulaştığı noktada yani gözden başlar ve kaynağa ulaşır. Mekan farkı gözetilmez. Gün 1şı̆̆ı istenilen koordinatta, tarihte ve saatteki konumuyla kullanılabilir.

Fotoğraf ile simülasyon arasındaki benzerlik aynı ise; simülasyon algoritması fiziksel doğrulara dayanıyorsa ve mekan hakkındaki bilgiler doğruysa, simüle edilmiş görüntü gerçek olmalıdır. Aksi durumda fizik kurallarında bir tutarsızlık var demektedir.

Spesifik özelliklere sahip farklı görüntüleme teknikleri ile aynı koşullar altında farklı sonuçlar elde edilebilir. Bu nedenle simülasyon ve fotoğraf arasındaki ana farklılıkların bilinmesi önemlidir. Fotoğraftaki ana teknik problem, fotoğrafın dijital veya kimyasal kaydedilmiş olmasına bakmaksızın görüntüleme sürecinde ortaya çıkmaktadır. Bulanıklılık, derinliğin kısıtlı olması, ışı̆̆ın kırılması gibi gerçek kameranın optik problemleri aşağıdaki etkilere sebep olmaktadır.

- Görüntünün kenarında kalan objelerin normalden daha eğri gözükür.

- $\quad$ Işık kaynakları olduğunda daha büyük görünür.

- Fotoğrafın derinliğinde keskin bir sınır vardır.

- $\quad$ Fotoğrafın merkez bölümü her zaman konturlara göre belirgin bir parlaklık taşır. 
Ekren, N. / Sosyal Bilimler Araştırmaları Dergisi. 2, (2007): 204-211

Flüoresan lambalar ve diğer deşarj lambalardaki renk korozyonları fotoğrafik görüntüye de aynen yansır. Bu sebeple fotoğrafta renk filtrelemesi çalışması yapılması gerekir. Simülasyonda benzer problemlere bir ölçüde sahip olmakla beraber bunların önlenmesi daha basit olmaktadır. Aydınlatma simülasyonunun kullanılmasının temel amacı aydınlatma tasarımcısının gerçekçi bir görüntü hayal etmesine yardımcı olmaktır.

Tecrübeler aydınlatma simülasyonunun aydınlatma tasarımının birinci basamağından kullanmaya başlamak gerektiğinin göstermektedir. Örneğin tavan yapısından dolayı direk gün ışığı alan ve gün 1şığının bir aydınlatma aracı olarak kullanan mekanlarda objelerin nasıl bir gölgeleme yapacağını ve hangi bölümlerin aydınlık olacağını önceden öğrenmek mümkündür. Diğer durumda oluşacak hatanın maliyeti yüksektir. Gölgeler kütüphanelerin, fabrikaların veya çalışma ofislerin tasarımında önemle dikkate alınması gereken bir faktördür. Homojenliği bozucu gölgeler oluşabilir. Bu da tasarımda hesaplanan aydınlık düzeyini \% 50 oranında azalmasına neden olabilir.

Görüntü simülasyonu ile yapılan çalışma neticesinde; yapılan tasarım uygulamaya geçilmeden sonuçlarını görme açısından eşsiz bir çözüm sunmaktadır. Böylece uygulama sonrasında klasik hesaplarda ve tasarımda ortaya çıkan hatalar için önceden önlem alınabilmektedir. Ayrıca önemli projelerde proje sahibine daha mekanın pafta üzerindeyken tüm dekoru ile olabilecek son halini gösterme imkanın sunulmaktadır.

Simülasyon teknolojisindeki gelişme sonucu;

- Hayali canlandırmaların gerçeğe yaklaşıyor.

- Hayali canlandırma fotoğraflardan daha hatasız ve doğru olabilir.

- Hayali canlandırmanın gerçekçi gösterimleri mümkündür.

- Hayali canlandırma çok kıymetli bir proje aracı olmuştur.

- Hayali kıyaslama ve karşılaştırma yöntemleri daha önemli hale gelmiştir.

- Hayali canlandırmada artık yeni araştırma konusu, karışık imajların ve tüm olasılıkların simülasyonunu gerçekleştirilmesidir.

Aydınlatma dersinde hesap yapmaya ağırlık vermek yerine, öğrenciye uygulamaya yönelik alan çalışması yaptırılabilinir. Bu çalışmada öğrencilerden öğrendikleri bilgileri sınamaları, doğru olanları saptamaları, yanlış olanları eleştirmeleri, iyileştirici öneriler getirmeleri ve en sonunda yönetmeliklere 
Ekren, N. / Sosyal Bilimler Araştırmaları Dergisi. 2, (2007): 204-211

dayanarak kontrol listesi oluşturmaları istenebilir. Öğrencilere aydınlatma projesi yaptırmak da yararı olabilir. Alan çalışması mı, aydınlatma projesi mi şeklinde bir karşılaştırma yapılacak olursa; üç boyutlu mekanda çalışma yapıldığı için alan çalışması, projeden daha verimli olabilir. Projeyi üç boyutlu görme yeteneğini yeterince kazanamamış öğrenciler için, aydınlatma projesi resim kağıdının üzerinde iki boyutlu olarak kalabilmektedir. Okulda yaptığı alan çalışması ve hazırladığı kontrol listesi, hayata atıldığı zaman projelendirme ve uygulamada ona kullanma kılavuzu görevi yapabilir. Herhangi bir ortamdaki görsel algılamanın kusursuz olabilmesi için aydınlığın niceliğinin ve niteliğinin, söz konusu ortamın özelliklerine uygun bir biçimde oluşturulması gereklidir.

\section{Sonuç}

Günümüzde gelişen teknolojinin katkısıyla piyasaya birçok yeni $1 s ̧ ı k$ kaynağı kazandırılmış, aydınlatma teknikleri geliştirilerek tasarımcıların hizmetine sunulmuştur. Bu hizmet, tasarımcıya müşterisine karşı bir sorumluluk yüklemektedir. Doğru 1şık kaynağını, doğru yerde ve doğru detayda kullanması gerekmektedir. Görüntü simülasyonu ile aydınlatma tasarımının hesaplanabilir ve görünebilir olması için etkili bir tasarım aracıdır.

$\mathrm{Bu}$ konuda eğitimcilerin sadece hesaba dayalı değil, kısa süreçte en yararı bilgiyi, kısa yollarla, kurallarının vermesi ve verilen bilgilerin özellikle yakın çevredeki uygulamalarda değerlendirilmesi kanımızca aydınlatma eğitiminin en önemli öğesidir. 
Ekren, N. / Sosyal Bilimler Araştırmaları Dergisi. 2, (2007): 204-211

\section{Kaynakça}

S.D.Elliot \& P.L. Miller, "Inside 3D Studio Release 4", New Riders Publishing, Indianapolis, 1994

S. Yılmazer \& C. Yener, “Aydınlatma Eğitimi Üzerine”, 3. Ulusal Aydınlatma Kongresi, İ.T.Ü. Taşkışla-İstanbul, 23-24 Kasım 2000

P. Kurtoğlu \& E. Erkin, "Bilgisayar Ortamında Aydınlatma Tasarımı SIVIEW Üç Boyutlu Aydınlatma Simülasyonu”, 3. Ulusal Aydınlatma Kongresi, İ.T.Ü. Taşkışla-İstanbul, 23-24 Kasım 2000

www.relux.ch erişim tarihi, mayıs 2008

www.siteco.com.tr erişim tarihi, mayıs 2008

www.radiance.com erişim tarihi, mayıs 2008

www.firat.edu.tr erişim tarihi, mayıs 2008

www.gazi.edu.tr erişim tarihi, mayıs 2008

www.itu.edu.tr erişim tarihi, mayıs 2008

www.ktu.edu.tr erişim tarihi, mayıs 2008

www.marmara.edu.tr erişim tarihi, mayıs 2008

www.kou.edu.tr erişim tarihi, mayıs 2008

www.sau.edu.tr erişim tarihi, mayıs 2008

www.yildiz.edu.tr erişim tarihi, mayıs 2008

www.halic.edu.tr erişim tarihi, mayıs 2008 